\title{
Change you can count on
}

\author{
Robert C. Robbins, MD
}

Thank you, John, for that kind introduction.

I want to begin by telling you what an exciting, meaningful, and humbling experience it has been to serve as your President for the past year.

I greatly appreciate all of the wonderful support that I have received from so many of you, especially our past President Robbin Cohen, as well as the members of the Council and the staff of PRRI, John Blackstone, Heather Nutter, Rebecca Bonsaint, and Crystal Beatrice. We are richly blessed to have such a special organization with simply outstanding members and their supportive families.

I want to thank my family. Debbie, Clay, and Craig are my foundation. They have each supported me despite the years of long hours and absenteeism.

Debbie and I have been married for 27 years. She is my best friend, and she gave up a successful law practice to dedicate herself to helping Clay, Craig, and me achieve our hopes and dreams. Thank you for everything that you have done for our family.

I also have been blessed with dedicated mentors, colleagues, and friends over the past 30 years, most of whom have been agents of change and innovative pioneers. I cannot possibly include everyone, but I would like to acknowledge some key individuals.

James D. Hardy and Arthur C. Guyton, at University of Mississippi, were my early mentors during medical school. Dr Hardy was a true surgical pioneer who performed the world's first human lung transplant in Jackson in 1963 and the first human heart transplant in 1964 using a chimpanzee donor. Steve Guyton's father was an internationally renowned researcher and dedicated teacher who should have been awarded the Nobel Prize for his work. A special thank you to the extraordinary group who trained me at Stanford: Dr Shumway who agreed to train me, Bruce Reitz who gave me my first and only real job that I have ever had, Phil Oyer, Ed Stinson, Craig Miller, Scott Mitchell, Jim Mark, Walter Cannon, and Vaughn Starnes. I feel blessed to have been trained by these men and to have known them as friends. I would also like to thank the current and

\footnotetext{
From the Department of Cardiothoracic Surgery, Stanford University Medical Center, Stanford, Calif.

Disclosures: The author has nothing to disclose with regard to commercial support. Read at the 38th Annual Meeting of The Western Thoracic Surgical Association, Maui, Hawaii, June 27-30, 2012.

Address for reprints: Robert C. Robbins, MD, Department of Cardiothoracic Surgery, Stanford University Medical Center, Falk Cardiovascular Research Bldg, 2nd Floor, 300 Pasteur Dr, Stanford, CA 94305-5247 (E-mail: robbins@ stanford.edu). J Thorac Cardiovasc Surg 2013;145:321-5 0022-5223/\$36.00

Copyright (c) 2013 Published by Elsevier Inc. on behalf of The American Association for Thoracic Surgery

http://dx.doi.org/10.1016/j.jtcvs.2012.11.001
}

past cardiothoracic faculty at Stanford who have made and continue to make my job rewarding and the department successful. Many of them are here today: Tom Burdon, Jim Fann, Mike Fischbein, Ramin Beygui, Joe Shrager, Randy Bolton, Richard Gregory, Richard Whyte, and Kai Ihnken. I have great admiration for all of the residents whom I have had the privilege to work with over the years, and I am happy to see so many of you here today.

I also thank our all of the department's staff, especially my personal assistant, Beverly Bonfert, who for the past 15 years has kept me between the ditches on a daily basis.

I am so grateful for the hard work that the program committee has done under the leadership of Gordon Cohen to give us this year's outstanding program. I did not know Gordon very well before this year, and I am pleased that he has decided to take his talents to North Beach. I appreciate Gordon's vision to personally convince President Emmert to be with us this year. I also thank Arnie Millstein for joining us.

Preparing my thoughts for this address was difficult because I share the mentality that Dr Shumway promulgated in his American Association for Thoracic Surgery Presidential Address entitled "Some thoughts from the other side of the table, or the last presidential address." 1 In those memorable remarks, Dr Shumway noted the annual program could accommodate 2 additional papers if the Presidential Address was eliminated. Because we have not evolved to Dr Shumway's vision, please indulge me for the next few minutes for some thoughts about our future.

Today, I would like to focus my comments on the topic of change, it's inevitability and the opportunity we all have to embrace it and shape the future of the field of human endeavor we have all given so much to and feel so passionately about.

We have often heard that you are either improving or declining, growing or decaying, living or dying... you cannot simply stay the same. The Buddha tells us "Everything changes. Nothing remains without change." We all experience personal changes, including physical changes, philosophical changes, social changes, financial changes, family changes, and career changes.

How many of you have an iPad (Apple Inc, Cupertino, Calif), a laptop, a smart phone? How many of you read newspapers or books online? Do you ever use SKYPE (Luxembourg) to visit with your children? It seems unthinkable that we once used rotary phones; listened to our music on record players, 8-track tapes, or even Walkman cassette players; and got our news from the nightly television news and sports information from the newspaper box scores. One of my regrets in life is that I didn't have the 
vision to start ESPN (Bristol, Conn). Information and communications technologies are rich with examples of rapid, recent change that seems to be coming at an accelerating pace. We as cardiothoracic surgeons have long been known as pioneers and innovators. We practice in a field of medicine, which, except for lung resection, did not exist 60 years ago. Today, we perform operations on a daily basis that could not have been imagined when our parents were young. The exciting birth and rapid evolution of our field, and the impact on individual lives and society as a whole are some of the reasons many of us were drawn to cardiothoracic surgery.

There is ample evidence that as a group we are innovators. However, like the rest of humankind, we can be resistant to change. As the economist John Kenneth Galbraith said, "Faced with the choice between changing one's mind and proving that there is no need to do so, almost everyone gets busy on the proof."

Maybe surgeons can be resistant to change because each and every time one of us "commits surgery" as Dr Shumway would say, there is a chance that the patient can die. It is only human to stick with what works. Once we have a repertoire that works, we do not want to change our way of performing critical operations. The upside can be unclear, and the downside can be severe. We are all artists, convinced that the way we conduct operations is the absolute best way to care for our patients.

Several years ago, there was a popular pizza commercial in which a man was standing in his doorway anxiously awaiting the arrival of 3 pizzas he had ordered. He's excited because not only was he allowed to order 3 pizzas for only $\$ 5$ each, but also he could mix and match toppings all he wanted! In the commercial, he takes possession of 3 identical pepperoni pizzas and closes the door. His wife appears and asks sarcastically why he always orders pepperoni when his options are unlimited? He looks ashamed and answers, "Because, I fear change." Like the guy in the commercial, most of us like things to be routine and predictable in our lives, but as Roseanne Cash says, "The key to change is to let go of fear." I hope over the next few minutes that I can encourage each of us to let go of fear, and not only be open to change but also to lead change in the areas of education, research, and clinical care.

\section{CHANGES IN EDUCATION}

Medical education in general and cardiothoracic surgical education specifically are currently in a time of great evolution and change.

There are 168 hours in a week, and for most of us in this room, our surgical training consisted of 7 to 10 years of every other or every third night in the hospital on call, spending more than 100 hours per week in the hospital. Whether you agree or disagree with the much-debated rationale for shorter work hours, the 80 -hour work week is here to stay and will likely become even more proscriptive. First, we must understand and accept this change. We might not like it, but we understand it. Second, we must embrace the challenge of training the best surgeons possible given these inevitable restrictions.

\section{Simulation}

To deal with the reduction in patient contact produced by work-hour restrictions, we must improve the efficiency and efficacy of the education of our students, residents, and fellows by further evolving the use of simulation to develop technical and decision making skills. Jim Fann has been an innovator in minimally invasive cardiac operations and simulation and continues to refine the simulation process. $\mathrm{He}$ is currently using a full cardiopulmonary bypass system for coronary and valvular procedures to assess the efficacy of this approach. I believe that the attendings and patients will be able to determine trainees who have spent significant time in intensive simulation. The impact will be visible, and these are changes we can and should embrace.

\section{Studying the Film}

We must also do a better job of preparing our trainees for excellence in all 6 core competencies of their curriculum: medical knowledge, technical abilities, professionalism, systems use, team care, and ethics. I envision that elite training programs in the future will use advanced, multiangled cameras to film every cardiothoracic case performed by a trainee. Just as in the National Football League, there will be a dedicated full-time video coordinator to break down and grade the films and to review each operation. Both the trainee and attending will be miked so that a running commentary of the operation can be used for educational advancement and departmental entertainment. I am certain that when residents perform a particularly smooth move, they will look over the drape and proclaim, "Go ahead and rack me because that the move will surely make the ESPN Top 10 Plays of the Day."

Atul Gawande ${ }^{2}$ recently wrote an article for The New Yorker in which he forwarded the concept that surgeons should consider using coaches because all professional athletes have coaches. I believe that we as surgical educators should all take the oath of the Positive Coaching Alliance and be committed to inspiring greatness in our trainees through positive coaching in all of the core competencies and lead by example. Training the next generation of leaders in cardiothoracic surgery may be our most important contribution to society, and we must embrace and lead the inevitable change that will come in the domain of cardiothoracic surgical education.

\section{TECHNIQUES AND TECHNOLOGIES}

The fundamental advancement of the field of cardiothoracic surgery has been so rapid because true pioneers 
and innovators relied on basic, translational, and clinical research to discover new knowledge to improve the health of patients. The development of cardiopulmonary bypass, intra-aortic balloon pumps, heart and lung transplantation, myocardial and neurologic protection strategies, single lung ventilation, minimally invasive surgical approaches, percutaneous valves, and smaller more effective left ventricular assist devices are all well-known examples of advances in our field that have improved the outcomes of the operations we are privileged to perform daily. These were changes driven by colleagues with vision.

I am also certain that there will continue to be advances in devices that we all use, including percutaneous mitral valve replacement, percutaneously delivered leadless pacemakers, percutaneously delivered and powered left ventricular assist devices, and even less invasive procedures that will be performed in hybrid rooms that will permit completion angiograms for all coronary artery bypass cases. We have developed a system in collaboration with the chief of electrophysiology and department of mechanical engineering that I believe may transform the treatment of atrial fibrillation. Virtually every procedure we do in the future will use image-guided therapies with even more advanced imaging technologies than those we have come to rely on today. Moreover, I believe there will be major advances from the domains of genomics, systems biology, bioengineering, bioinformatics, and stem cell research.

\section{GENOMICS AND BIOINFORMATICS}

The human genome project took 10 years and 3 billion dollars to map the entire genome of 1 single individual. Moore's law is a well-known computer science observation that "computing power" as a function of speed and transistor density doubles approximately every 18 months. I believe advances in genomic sequencing will follow a similar curve going forward: The value of obtaining an entire human genome in 10 years for $\$ 3$ billion has now been replaced with sequencing an entire genome in 48 hours for less than $\$ 1000$. This rapid progression has eclipsed the rate of progress predicted by Moore's law because if this technology had followed Moore's law, today it would cost $\$ 5$ million dollars to sequence a single human genome. Some experts believe that this cost will soon be less than $\$ 50$ per patient and that most health systems will eventually pay patients to have their genomic data to guide the future practice of medicine. I am certain that everyone in this room will be able to carry their own genomic digital data on their smart phone within the next decade. Or maybe we will all be "chipped," and first responders and clinical caregivers will be able to read our histories with secret decoder rings. Change is inevitable whether you agree with it or not. The challenge we face is to shape the changes in ways we think will benefit patients and future generations of cardiothoracic surgeons.

Genetic sequencing of entire populations has already begun in places such as Iceland, where the Icelandic Parliament passed legislation to create a medical database, including genetic data. Genomic-guided therapies for lung cancer and coronary artery disease will be customized to the patient's genetic makeup. However, we need to have more focused research designed to better understand what this genetic information means for each patient. Sophisticated bioinformatic analysis of genetic data must be combined with phenotypic data, including environmental, proteomic, metabolomic, and epigenetic factors that may affect an individual patient's health. The same challenge essentially is being addressed in business settings under the heading of "The Big Data Problem." Simply, "Big Data" is the aggregation of disparate sources of information and the analysis of more complete data sets with powerful, computer-based analytic tools. It is a model that bears scrutiny. In Eric Topol's recent book The Creative Destruction of Medicine, he describes how the digital revolution will create better health care.

\section{INDUCIBLE PLURIPOTENT STEM CELLS}

In the area of stem cell research, I believe embryonic stem cells and inducible pluripotent stem (IPS) cell biology will have powerful effects on the advancement of the treatment of human diseases.

Our group has worked for more than 10 years on cardiac stem cell biology, and we were recently awarded a \$20 million grant from the California Institute for Regenerative Medicine that will help us be the first group in the world to inject human embryonic stem cells into the human heart.

The process of producing IPS cells was discovered by Yakamana in 2005. Adult somatic cells, such as fibroblast from the skin and more recently blood cells, can be programmed through gene therapy to revert back to a pluripotent or embryonic state and then directly differentiated to become the desired cell, such as heart cells or brain cells. The use of IPS cells for therapeutic interventions to treat heart failure, diabetes, or Parkinson's disease holds great promise because these are autologous cells that will not be rejected. In addition, the use of IPS cells avoids the moral and ethical issues associated with embryonic stem cells. Our valued collaborators Qian and colleagues, ${ }^{3}$ at the Gladstone Institute in San Francisco, have developed a technique that removes the IPS cell step and directly differentiates adult fibroblasts to cardiomyocytes. Moreover, Qian and colleagues recently demonstrated that this technique can be used in vivo to turn cardiac fibroblasts into cardiomyocytes and therefore set the stage for future repair of human myocardial damage. 
Our cardiac stem cell team is developing 2 other potentially powerful uses of IPS cells beyond therapeutic interventions. The first is to use these cells to discover novel mechanisms of disease processes and to identify new targets for the development of drugs or antibodies to treat diseases such as congestive heart failure. One could imagine conducting human clinical trials in a Petri dish in the near future to determine whether new drugs are effective and efficacious in the perturbation of targets important in certain disease processes. We plan to develop IPS cell lines from patients with Marfan syndrome to test the efficacy of important new mechanisms for the development of aortic aneurysms through a Mir 29-dependent pathway, which was recently discovered and published by Merk and colleagues ${ }^{4}$ at Stanford. The other platform for the use of IPS cells will be in drug screening for toxicity. Cardiac toxicity is a major limitation in the development of drugs. The pre-animal screening of every drug that is ingested for cardiac toxicity is currently performed in Chinese hamster ovary cells to assess calcium channel function and then impute possible cardiac toxicity from these primitive screening tests.

I believe that every drug that is developed for human use soon will be tested in a platform that uses human IPS cells that have been differentiated to beating human cardiac cells. The use of patch clamping techniques and other automated and scalable technologies to determine electrocardiographic abnormalities, such as prolonged QT syndrome, one of the most important and lethal drug-induced arrhythmias, will be possible using this IPS cell platform.

Cisapride, a multibillion dollar drug widely used for the treatment of gastric dysmotility, was removed from the market because of death from prolonged QT syndrome that was not discovered in the primitive hamster cell screening that was performed. The use of an IPS cell screening platform could have avoided these deaths and saved the drug company billions of dollars.

Our group, under the leadership of Joe Wu, seeks to develop 1000 IPS cell lines from patients with dilated and hypertrophic cardiomyopathies, coronary artery disease, atrial fibrillation, Marfan syndrome, and a variety of other known cardiovascular diseases. We will build this library from old and young patients, men and women, and all races and ethnicities to determine the efficacy and safety of drugs not only in normal beating cardiac cells but also in cardiac cells from patients with well-defined diseases.

\section{CARDIOTHORACIC CARE DELIVERY}

Just as we should focus our energy on finding more efficient and effective ways to train the next generation of cardiothoracic surgeons, I believe that we should also focus on improving clinical care in a milieu where the inevitability of major changes will evolve in our health care system. The United States generates \$16 trillion dollars per year in gross domestic product, the government collects $\$ 2.2$ trillion dollars in Federal taxes and spends $\$ 3.8$ trillion dollars annually (that is right, the US Government spends approximately $\$ 10$ billion dollars every day), thereby adding $\$ 1.6$ trillion dollars to our national debt each year, which has now reached \$16 trillion dollars. There are \$24.4 trillion in obligations for current Medicare participants above and beyond projected revenues from their payroll taxes, benefit taxes, premium payments, and assets of the Medicare trust fund. This is simply not sustainable, and change is certainly needed in this domain and is inevitable.

A little closer to home, according to the World Health Organization, total health care spending in the United States was $15.2 \%$ of its gross domestic product in 2008 , the highest rate in the world.

Yet, despite having the most expensive health care system in the world, the United States ranked last overall compared with 6 other industrialized countries in a study conducted by the Commonwealth Fund and published in June 2010. The study attempted to measure health care delivery across a range of parameters, including quality and efficiency. In brief, it said the United States stands out for not getting good value for its health care dollars, ranking last despite spending more than $\$ 7000$ per capita on health care in 2007. The Netherlands, which ranked first overall among the 7 countries included in the study, spent less than $\$ 4000$.

In the clinical domain, there are 3 areas that will require deep commitment over the coming years. Quality, cost, and customer service will be used not only to judge performance but also to be the parameters by which we are paid. Therefore, I encourage all of us to become more involved and aligned with our hospitals to better understand the financial balance sheet of our cardiovascular service lines. I predict that it will be extremely difficult for any of us to earn the level of income that we consider reasonable without significant alignment with our hospitals. This is certainly true in some academic centers and large health care systems such as Kaiser, where alignment between the professional and hospital technical revenues and the expenses are commonplace. It is likely that most of us will practice cardiothoracic surgery in an integrated system in the future and that managing both hospital and outpatient costs will be important to all of us as members of a larger team.

We will need to achieve the highest quality outcomes at the lowest possible cost to remain relevant and competitive. Our quality data have been extensively tracked and scrutinized for approximately 2 decades, and despite the fact that we are operating on patients who are sicker with more comorbidities, the results for all cardiothoracic operations have improved over the past 2 decades; the 2011 national mean operative mortality for coronary artery bypass grafting was $2.3 \%$, which is truly remarkable. However, we will need to continue to look for ways to improve all 
quality metrics over the coming years. My prediction is that once we are paid on the basis of our results, we will become more conservative in patient selection and will ultimately serve as the gatekeepers for the providers, and de facto rationing will be achieved by the government. Moreover, I anticipate in the near future that we will each receive a detailed cost analysis for how much it costs the hospital to care for our patients, and those who achieve the best quality outcomes for the lowest cost will be financially rewarded and will remain competitive. We should all look for technologic interventions that will help us achieve our objectives of higher quality at lower costs.

In the near future, stethoscopes may be replaced with handheld miniature echocardiography devices. These devices currently cost approximately $\$ 6000$, but the price will certainly decrease as the market becomes more competitive. We have recently funded a pilot study to give 10 cardiac transplant recipients these handheld devices, train them to acquire satisfactory images of their left ventricles, and to email us these images frequently with the objective of reducing the number of hospital visits and endomyocardial biopsies, thereby reducing costs. This is change that will require work with multidisciplinary teams to deliver the best care possible to our patients. We will need to invest in technologic solutions, such as the Toyota Lean (Torrance, Calif) and GE Six Sigma (Fairfield, Conn) methodologies to improve our efficiency and efficacy to remain competitive.

The construction and maintenance of sophisticated bioinformatics datasets will be complemented by the adaptation of so-called "cloud-based" computing resources and anywhere, anytime display and delivery mechanisms. We will be able to leverage technology to follow patients' biometric data wirelessly and meet with them by video clinics from their home computers or smart phones.

We are developing such a system at Stanford called the "Cardinal Commitment," which we believe will improve patient care quality and reduce cost.

\section{STRATEGIC PLANNING}

Finally, there will be changes in our association over the next decade. To guide the process of rational, thoughtful deliberate change in our organization, the council has approved a request to move forward with a strategic planning process that will develop a roadmap for the future of the Western Thoracic Surgical Association. I have asked Robbin Cohen to help me lead this project over the next several months in collaboration with a consultant group that specializes in health care strategic planning. You will all receive a questionnaire that will provide important data to help the working group through the planning process.

We can count on change and should lead change that will produce better trained cardiothoracic surgeons, innovative discoveries, and improved outcomes for our patients. We must be careful to make changes that are thoughtful and strategic, and not change just to follow the latest fad. We need to change for the better. We should be careful to avoid strategies like those that led to New Coke (The Coca-Cola Company, Atlanta, Ga) or Tiger's new golf swing. I believe that technology will be the key enabling leverage that we will use to fulfill our missions, but the care of the future must be high touch as well as high tech. Abraham Verghese, one of our Stanford colleagues and author of the great novel Cutting for Stone, emphasizes the importance of the physical examination and taking the time to listen to the hopes and dreams of our patients. We are all so blessed and privileged to be cardiothoracic surgeons. I believe that we can invent the future of our field, and that it will be a future full of change for good, change that we as surgeons, but more important, our patients and their loved ones can count on.

Thank you for your patience and attention.

\section{References}

1. Shumway NE Jr. Some thoughts from the other side of the table, or the last presidential address. J Thorac Cardiovasc Surg. 2011;142:1296-8.

2. Gawande A. Personal best: top athletes and singers have coaches. Should you? The New Yorker Annals of Medicine. October 3, 2011.

3. Qian L, Huang Y, Spencer CI, Foley A, Vedantham V, Liu L, et al. In vivo reprogramming of murine cardiac fibroblasts into induced cardiomyocytes. Nature. 2012;485:593-8.

4. Merk DR, Chin JT, Dake BA, Maegdefessel L, Miller MO, Kimura N, et al. miR $29 \mathrm{~b}$ participates in early aneurysm development in Marfan syndrome. Circ Res. 2012;110:312-24 